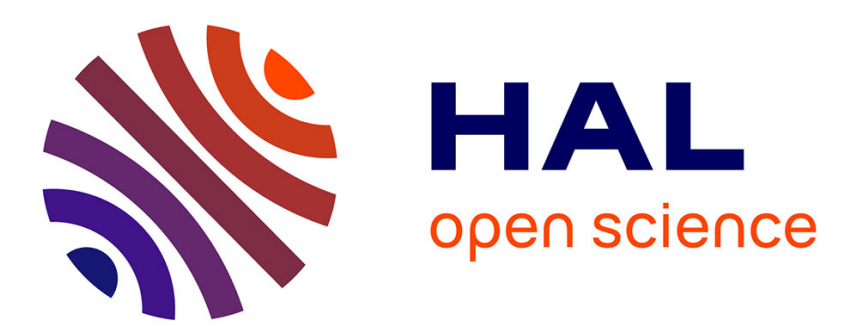

\title{
Recent progress in the energy characterization of the mechanical behaviour of rubbers

\author{
Jean-Benoit Le Cam
}

\section{To cite this version:}

Jean-Benoit Le Cam. Recent progress in the energy characterization of the mechanical behaviour of rubbers. 11th European Conference on Constitutive Models for Rubber, 2019, Jun 2019, Nantes, France. pp.147-150, 10.1201/9780429324710-26 . hal-02499973

\section{HAL Id: hal-02499973 \\ https://hal-univ-rennes1.archives-ouvertes.fr/hal-02499973}

Submitted on 23 Sep 2020

HAL is a multi-disciplinary open access archive for the deposit and dissemination of scientific research documents, whether they are published or not. The documents may come from teaching and research institutions in France or abroad, or from public or private research centers.
L'archive ouverte pluridisciplinaire HAL, est destinée au dépôt et à la diffusion de documents scientifiques de niveau recherche, publiés ou non, émanant des établissements d'enseignement et de recherche français ou étrangers, des laboratoires publics ou privés.

\section{(c)(1)}

Distributed under a Creative Commons Attribution| 4.0 International License 


\title{
Recent progress in the energy characterization of the mechanical behaviour of rubbers
}

\author{
J.-B. Le Cam ${ }^{\star}$ \\ * Univ Rennes, CNRS, IPR (Institut de Physique de Rennes) \\ UMR 6251, F-35000 Rennes, France
}

\begin{abstract}
The hysteresis observed in the mechanical response of rubbers (especially filled rubbers) is classically assumed to be fully due to viscosity. Complete energy balances carried out during cyclic deformation show that viscosity is not systematically the preponderant contribution to the hysteresis loop: the mechanical energy brought to the material is not entirely dissipated into heat but can be predominantly used by the material to change its microstructure. Predicting changes in temperature, and consequently the self-heating, is therefore not possible from the mechanical response only. This has been evidenced by defining a ratio in terms of energy. A new way of interpretation of the rubber resistance can therefore by found through its ability to store mechanical energy.
\end{abstract}

\section{INTRODUCTION}

Elastomers are widely used in many industries such as automotive, nuclear, or civil engineering for their high deformability, high damping and resistance to fatigue. Such properties are generally obtained by adding fillers in the rubber matrix, which induces or increases the hysteresis loop in the mechanical response. Classically, the mechanical energy involved in the hysteresis loop is assumed to be mainly dissipated into heat. Nevertheless, several observations question this assumption:

- the mechanical response of some elastomers exhibits a hysteresis loop only when strain-induced crystallization (SIC) occurs, typically in case of unfilled natural rubber (NR) (Samaca Martinez, Le Cam, Balandraud, Toussaint, and Caillard 2013b). In this case, no self-heating accompanies the mechanical cycles,

- the mechanical hysteresis can be not timedependent (D'Ambrosio, De Tommasi, Ferri, and Puglisi 2008, A. Dorfmann and Ogden 2003, Rey, Chagnon, Favier, and Le Cam 2014, Vandenbroucke, Laurent, Hocine, and Rio 2010),

- if all the energy contained in the hysteresis loop were due to viscosity, the self-heating would be much higher than that observed experimentally.

One can therefore wonder about the nature and the time dependency of the phenomena involved in the formation of the hysteresis loop and about the real contribution of the intrinsic dissipation to it. To go further, it should be noted that two other phenomena can contribute to the mechanical hysteresis:

(a) the thermal dissipation $\left(d_{2}\right)$ (in non adiabatic test conditions). If heat is exchanged with the specimen's outside, a hysteresis loop in the stretchstress relationship forms, even for purely elastic materials (the current temperature appearing in the elastic coupling). In most of the homogeneous tests ${ }^{1}$ performed, considering the thermal properties of elastomers, the loading rate is sufficiently high and the thermal dissipation does not really contribute to the mechanical hysteresis,

(b) the change in microstructure. In this case, all the work done to the system is not measured as a temperature change (see for instance the recent studies by (Mott, Giller, Fragiadakis, Rosenberg, and Roland 2016) on polyurea). A part of the mechanical energy is used by the material to reorganize.

Such analysis is classically carried out in metallic materials, since the pioneering work by (Farren and Taylor 1925) and (Taylor and Quinney 1934) who measured the latent energy remaining after cold working in a metal under quasi-static monotonous loadings. Today, the fraction of the anelastic deformation energy rate irreversibly converted into heat is studied

\footnotetext{
${ }^{1}$ in terms of heat source field, see Section 2
} 
through the Taylor-Quinney ratio (Chrysochoos 1985, Chrysochoos, Maisonneuve, Martin, Caumon, and Chezeau 1989, Mason, Rosakis, and Ravichandran 1994, Rittel 1999, Oliferuk, Maj, and Raniecki 2004). Polymers have then benefited from this approach (Rittel 2000, Rittel and Rabin 2000, Benaarbia, Chrysochoos, and Robert 2014, Benaarbia, Chrysochoos, and Robert 2015). Concerning elastomers, three recent studies investigate the energetic behavior and the energy storage during deformation (Le Cam 2017, Lachhab, Robin, Le Cam, Mortier, Tirel, and Canevet 2018, Loukil, Corvec, Robin, Miroir, Le Cam, and Garnier 2018). From these studies, the energy storage in different types of elastomers, filled and unfilled, crystallizing or not, can be discussed. This is the aim of the present paper. Section 2 presents the thermodynamics framework to carry out energy balance. Section 3 presents a typical experimental setup which consists in uni-axial cyclic tensile tests. Section 4 gives the results of energy balances carried out for a natural rubber, a thermoplastic polyurethane (TPU) and a nitrile rubber. Concluding remarks close the paper.

\section{THERMODYNAMICS FRAMEWORK}

The energy balances require the calculation of:

- a quantity $P_{\text {hyst }}^{\text {cycle }}$, calculated in $W / m^{3}$, obtained by dividing the energy involved in the hysteresis

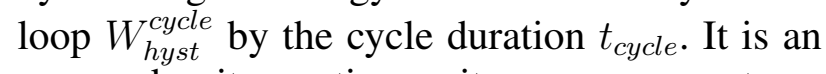
energy density per time unit or an energy rate,

- the heat power density at any time during the deformation $s(t)$, named heat source in the following. All of these quantities and their calculation are presented in Lachhab et al. (2018) and Loukil et al. (2018).

\subsection{Focus on the heat source calculation in case of homogeneous tests}

Most of mechanical tests are conducted under nonadiabatic conditions. The temperature measured is therefore affected by heat diffusion, possible temperature gradients at the surface of the undeformed specimen and external heat sources (for instance radiations). Therefore, changes in temperature are not only due to the material deformation. In this study, a "more intrinsic" quantity, namely the heat source, is determined from the heat diffusion equation applied to the temperature field measurements. For this purpose, the thermomechanical framework described in Nguyen et al. (1983) is applied. The local state axiom is assumed (Boccara 1968). Any thermodynamical system out of equilibrium is considered as the sum of several homogeneous subsystems at equilibrium. The thermodynamic process, i.e. the deformation, is considered as a quasi-static phenomenon. The equilibrium state of each volume material element is defined by $n$ state variables: the absolute temperature $T$, the deformation gradient tensor $\mathbf{F}$ and $m(=n-2)$ internal tensorial variables $\boldsymbol{\xi}_{\alpha}$. Using the two principles of thermodynamics, the local form of the heat diffusion equation is written as follows (Balandraud and Le Cam 2014):

$$
\begin{aligned}
& \rho C \dot{T}-\operatorname{Div}\left(\boldsymbol{\kappa}_{\mathbf{0}} \operatorname{Grad} T\right)= \\
& \underbrace{\mathcal{D}_{\text {int }}+T \frac{\partial \boldsymbol{\Pi}}{\partial T}: \dot{\mathbf{F}}+T \sum_{\beta=1}^{m} \frac{\partial \boldsymbol{A}_{\boldsymbol{\beta}}}{\partial T}: \dot{\boldsymbol{\xi}_{\boldsymbol{\beta}}}}_{s}+R
\end{aligned}
$$

where $\kappa_{0}$ is a positive semi-definite tensor characterizing the thermal conductivity of the material. $\rho$ and $C$ are the density and the specific heat, respectively. $s$ denotes the overall heat source induced by the deformation process. The term $\mathcal{D}_{\text {int }}$ corresponds to the intrinsic dissipation (also named mechanical dissipation). The term $T \frac{\partial \Pi}{\partial T}: \dot{\mathbf{F}}$ corresponds to the heat source due to entropic and non-entropic couplings between temperature and strain, where $\Pi$ is the nominal stress tensor. The term $T \frac{\partial \boldsymbol{A}_{\boldsymbol{\beta}}}{\partial T}: \dot{\boldsymbol{\xi}_{\boldsymbol{\beta}}}$ corresponds to the other thermomechanical couplings (for instance related to changes in the material microstructure). The term $R$ is related to the external heat sources.

As temperature field provided by infrared camera is bidimensional, the heat diffusion equation can be simplified by averaging over the direction corresponding to the material thickness. In the case of uniform heat sources fields, a OD formulation of the heat diffusion equation has been proposed in Chrysochoos and Louche (2000). Considering temperature variation $\theta$ instead of temperature and assuming $R$ to be constant during the deformation process, it writes:

$\rho C\left(\dot{\theta}+\frac{\theta}{\tau}\right)=s$

where $\tau$ is a time characterizing the heat exchanges between the specimen and its surrounding.

\subsection{Energy balance}

Both the mechanical and the calorific responses are required. The mechanical response provides the energy and its rate $P_{\text {hyst }}^{\text {cycle }}$ corresponding to the hysteresis loop. Integrating the heat source with respect to time over one cycle gives the mean intrinsic dissipation $\tilde{\mathcal{D}}_{\text {int }}$ :

$\tilde{\mathcal{D}}_{\text {int }}=\frac{1}{t_{\text {cycle }}} \int_{\text {cycle }} s d t$ 
The difference between $P_{\text {hyst }}^{\text {cycle }}$ and $\tilde{\mathcal{D}}_{\text {int }}$ gives the energy rate stored at each cycle:

$P_{\text {stored }}^{\text {cycle }}=P_{\text {hyst }}^{\text {cycle }}-\tilde{\mathcal{D}}_{\text {int }}$

Moreover, even though rubber elasticity is mainly entropic, non-entropic effects (change in the internal energy) can take place (Treloar 1973, Flory 1961). They can be investigated by comparing the strain power density with the heat source at any time during the mechanical cycles. This enables us to highlight some kinetics differences in internal energy change between loading and unloading if any, typically in NR (see Le Cam (2017)). To further discuss on the relative contribution of the energy stored in the hysteresis loop of rubbers, a ratio $\gamma_{s e}$ has been proposed. It is written in terms of energy as follows:

$\gamma_{s e}=\frac{W_{\text {stored }}^{\text {cycle }}}{W_{\text {hyst }}^{\text {cycle }}}$

- if $\gamma_{s e}$ tends to 0 , no energy is stored during the deformation. The whole hysteresis loop is due to the intrinsic dissipation,

- if $\gamma_{s e}$ tends to 1 , the whole hysteresis loop is due to energy stored and no intrinsic dissipation is detected. This is typically the case in unfilled natural rubber (Samaca Martinez, Le Cam, Balandraud, Toussaint, and Caillard 2013b), for which the energy is released with a different kinetics.

\section{EXPERIMENTAL SET-UP}

Three materials are considered in the discussion: an acrylonitrile butadiene rubber (NBR) unfilled and carbon black filled, an unfilled natural rubber and a polyurethane (TPU). Further information on the materials and the specimens used is provided in Loukil et al. (2018), Le Cam (2017) and Lachhab et al. (2018), respectively. The mechanical tests consist in applying sets of several cycles at an increasing maximum stretch $\lambda_{\max }$. The number of cycles at a given maximum stretch is chosen in such a way that the last one is mechanically and thermally stabilized. Several loading rates were applied.

\subsection{Temperature measurements}

Temperature measurements were carried out by using FLIR infrared cameras. The camera model, the integration time, the acquisition frequency, the thermal resolution or noise equivalent temperature difference, the spatial resolution and the surface emissivity are given in Le Cam (2017), Lachhab et al. (2018) and Loukil et al. (2018). The infrared cameras are switched on at least 3 hours before testing in order to ensure its internal temperature to be stabilized. The calibration of camera detectors was performed with a black body using a Non-Uniformity Correction (NUC) procedure. The mean temperature of two zones of interest is considered. They are located at the centres of the tested and reference specimens. A suitable movement compensation technique is used to track the centre of the tested specimen (see (Pottier, Moutrille, Le Cam, Balandraud, and Grédiac 2009) and (Samaca Martinez, Le Cam, Balandraud, Toussaint, and Caillard 2013a) for further information on this technique). The reference specimen provides the ambient temperature during the test. The temperature variation of the tested specimen is corrected with respect to changes in the ambient temperature if any.

\section{RESULTS AND DISCUSSION}

The heat source $s$ (in $W \cdot m^{-3}$ ) is calculated for each stabilized cycle at different maximum stretches. $P_{\text {hyst }}^{\text {cycle }}$ and $\tilde{\mathcal{D}}_{\text {int }}$ are then considered for calculating $\gamma_{s e}$. Figure 1 summarizes the energetic behavior of the three materials considered. It will be fully presented and discussed during the talk.

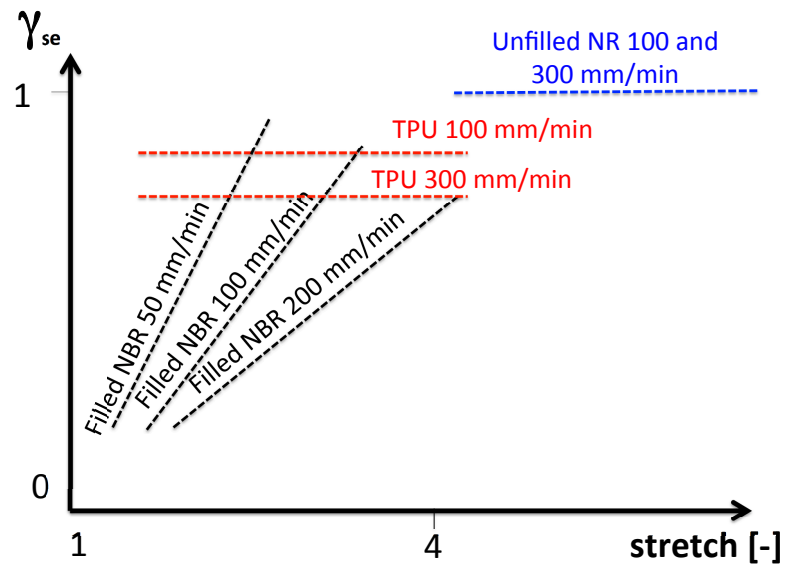

Figure 1. Map of the energetic behavior of the materials considered

\section{CONCLUSION}

Recent studies reviewed in this paper investigate the energetic behavior and the energy storage during deformation in different types of elastomers (Le Cam 2017, Lachhab, Robin, Le Cam, Mortier, Tirel, and Canevet 2018, Loukil, Corvec, Robin, Miroir, Le Cam, and Garnier 2018). A ratio $\gamma_{s e}$ has been proposed to relativise the energy stored at each cycle. Results show that viscosity is not systematically the preponderant contribution to the hysteresis loop: the mechanical energy brought to the material is not entirely dissipated into heat and can be mainly used by the material to change its microstructure. This ratio is of a first importance for designing rubber parts as it characterizes the greater or lesser ability of the rubber to absorb mechanical energy without damaging. 
Our industrial and academic partners are warmly acknowledged for their financial support and the fruitful discussions. We also thank the National Center for Scientific Research (MRCT-CNRS and MI-CNRS), Rennes Metropole and Region Bretagne for their financial support.

\section{REFERENCES}

A. Dorfmann, K. N. G. F. and R. W. Ogden (2003). Modelling dilatational stress softening of rubber. In J. Busfield and A. Muhr (Eds.), Constitutive Models for Rubber III, pp. 253261. Balkema, London.

Balandraud, X. and J.-B. Le Cam (2014). Some specific features and consequences of the thermal response of rubber under cyclic mechanical loading. Archive of Applied Mechanics 84(6), 773-788.

Benaarbia, A., A. Chrysochoos, and G. Robert (2014). Kinetics of stored and dissipated energies associated with cyclic loadings of dry polyamide 6.6 specimens. Polymer Testing 34, $155-167$.

Benaarbia, A., A. Chrysochoos, and G. Robert (2015). Influence of relative humidity and loading frequency on the pa6.6 thermomechanical cyclic behavior: Part ii. energy aspects. Polymer Testing 41, 92 - 98.

Boccara, N. (1968). Les principes de la thermodynamique classique. In PUF coll. SUP.

Chrysochoos, A. (1985). Energy balance for elastic plastic deformation at finite strain (in french). Journal de Mécanique Appliquée 5, 589-614.

Chrysochoos, A. and H. Louche (2000). An infrared image processing to analyse the calorific effects accompanying strain localisation. Int J Eng Sci 38, 1759-1788.

Chrysochoos, A., O. Maisonneuve, G. Martin, H. Caumon, and J. O. Chezeau (1989). Plastic and dissipated work and stored energy. Nuclear Engineering and Design 114, 323-333.

D’Ambrosio, P., D. De Tommasi, D. Ferri, and G. Puglisi (2008, APR). A phenomenological model for healing and hysteresis in rubber-like materials. International Journal of Engineering Science 46(4), 293-305.

Farren, W. S. and G. I. Taylor (1925). The heat developed during plastic extension of metals. Proceedings of the Royal Society of London A: Mathematical, Physical and Engineering Sciences 107(743), 422-451.

Flory, P. J. (1961). Thermodynamics relation for high elastic materials. Transactions of the Faraday Society 57, 829-838.

Lachhab, A., E. Robin, J.-B. Le Cam, F. Mortier, Y. Tirel, and F. Canevet (2018). Energy stored during deformation of crystallizing tpu foams. Strain e12271.

Le Cam, J.-B. (2017). Energy storage due to strain-induced crystallization in natural rubber: the physical origin of the mechanical hysteresis. Polymer 127, 166-173.

Loukil, M., G. Corvec, E. Robin, M. Miroir, J.-B. Le Cam, and P. Garnier (2018). Stored energy accompanying cyclic deformation of filled rubber. European Polymer Journal 98, 448 455.

Mason, J., A. Rosakis, and G. Ravichandran (1994). On the strain and strain rate dependence of the fraction of plastic work converted to heat: an experimental study using high speed infrared detectors and the kolsky bar. Mechanics of Materials 17(2), 135 - 145.

Mott, P., C. Giller, D. Fragiadakis, D. Rosenberg, and C. Roland (2016). Deformation of polyurea: Where does the energy go? Polymer 105, 227 - 233.

Nguyen, Q., P. Germain, and P. Suquet (1983). Continuum thermodynamics. J Appl Sci 50, 1010-1020.
Oliferuk, W., M. Maj, and B. Raniecki (2004). Experimental analysis of energy storage rate components during tensile deformation of polycrystals. Materials Science and Engineering: A 374(1), $77-81$.

Pottier, T., M.-P. Moutrille, J.-B. Le Cam, X. Balandraud, and M. Grédiac (2009). Study on the use of motion compensation technique to determine heat sources. application to large deformations on cracked rubber specimens. Experimental Mechanics 49, 561-574.

Rey, T., G. Chagnon, D. Favier, and J.-B. Le Cam (2014). Hyperelasticity with rate-independent microsphere hysteresis model for rubberlike materials. Computational Materials Science 90, 89 - 98.

Rittel, D. (1999). On the conversion of plastic work to heat during high strain rate deformation of glassy polymers. Mechanics of Materials 31(2), 131 - 139.

Rittel, D. (2000). An investigation of the heat generated during cyclic loading of two glassy polymers. Part I: Experimental. Mechanics of Materials 32(3), 131-147.

Rittel, D. and Y. Rabin (2000). An investigation of the heat generated during cyclic loading of two glassy polymers. Part II: Thermal analysis. Mechanics of Materials 32(3), 149-159.

Samaca Martinez, J. R., J.-B. Le Cam, X. Balandraud, E. Toussaint, and J. Caillard (2013a). Mechanisms of deformation in crystallizable natural rubber. part 1: Thermal characterization. Polymer 54, $2717-2726$.

Samaca Martinez, J. R., J.-B. Le Cam, X. Balandraud, E. Toussaint, and J. Caillard (2013b). Mechanisms of deformation in crystallizable natural rubber. part 2: Quantitative calorimetric analysis. Polymer 54, $2727-2736$.

Taylor, G. I. and H. Quinney (1934). The latent energy remaining in a metal after cold working. Proceedings of the Royal Society of London A: Mathematical, Physical and Engineering Sciences 143(849), 307-326.

Treloar, L. R. G. (1973). The elasticity and related properties of rubbers. Reports on Progress in Physics 36(7), 755.

Vandenbroucke, A., H. Laurent, N. A. Hocine, and G. Rio (2010). A Hyperelasto-Visco-Hysteresis model for an elastomeric behaviour: Experimental and numerical investigations. Computational Materials Science 48(3), 495-503. 